\title{
Euro-American Discussion Document on Entry- Level and Advanced Practice in Nuclear Medicine
}

\author{
Kristen Waterstram-Rich ${ }^{1}$, Peter Hogg ${ }^{2}$, Giorgio Testanera ${ }^{3}$, Helena Medvedec ${ }^{4}$, Suzanne E. Dennan ${ }^{5}$, Wolfram Knapp ${ }^{6}$, \\ Nigel Thomas ${ }^{7}$, Kathy Hunt, CNMT $^{8}$, Martha Pickett, CNMT, FSNMTS ${ }^{9}$, Aaron Scott, CNMT, NMAA ${ }^{10}$, and Gary Dillehay ${ }^{11}$ \\ ${ }^{I}$ College of Health Sciences and Technology, Rochester Institute of Technology, Rochester, New York; ${ }^{2}$ Department of Radiography, \\ University of Salford, Greater Manchester, United Kingdom; ${ }^{3}$ Department of Nuclear Medicine, Istituto Clinico Humanitas, Rozzano, \\ Milan, Italy; ${ }^{4}$ Department of Nuclear Medicine and Radiation Protection, Clinical Hospital Centre Zagreb, Zagreb, Croatia; \\ ${ }^{5}$ Department of Diagnostic Imaging, St. James Hospital, Dublin, Ireland; ${ }^{6}$ Clinic for Nuclear Medicine, Hannover University Medical \\ School, Hannover, Germany; ${ }^{7}$ Department of Clinical Radiology, Trafford General Hospital, England, United Kingdom; ${ }^{8}$ Department \\ of Nuclear Medicine, Baptist College of Health Sciences, Memphis, Tennessee; ${ }^{9}$ Alexander, Arkansas; ${ }^{10}$ Nuclear Medicine, Conyers, \\ Georgia; and ${ }^{11}$ Department of Nuclear Medicine, Northwestern Memorial Hospital, Chicago, Illinois
}

$\mathbf{T}$ he European Association of Nuclear Medicine Technologist Committee (EANMTC) and the Society of Nuclear Medicine Technologist Section (SNMTS) meet biannually to consider matters of mutual importance. These meetings are held during the SNM and EANM annual conferences. For several years, within these meetings, EANMTC and SNMTS have considered the value of having a Euro-American initiative in defining entry-level and advanced practice competencies for nuclear medicine radiographers (NMRs) and nuclear medicine technologists (NMTs). In June 2009, during the SNM annual conference in Toronto, it was agreed that a Euro-American working party would be established to consider advanced practice. It was recognized that any consideration of a definition for advanced practice would be predicated on an understanding or definition of entry-level practice. As a result, both types of practice would have to be considered. This discussion document outlines some of the background issues associated with advanced practice generally and specifically within nuclear medicine. The primary purpose of this document is to stimulate debate, on a Euro-American level, about the perceived value of advanced practice for NMRs and NMTs within nuclear medicine and to develop an internationally accepted list of entrylevel competencies and scope of practice for NMRs and NMTs within nuclear medicine.

It was not the working party's intention to say whether countries should or should not attempt to advance their prac-

Received Aug. 1, 2011; accepted Aug. 1, 2011.

For correspondence or reprints contact: Kristen Waterstram-Rich, Rochester Institute of Technology, College of Health Sciences and Technology, 153 Lomb

Memorial Dr., Rochester, NY 14623.

E-mail: kmw4088@rit.edu

Published online Aug. 18, 2011.

COPYRIGHT ( 2011 by the Society of Nuclear Medicine, Inc.

DOI: 10.2967/jnmt.111.096354 tice; this would be for them to determine. However, the working party did wish to develop a Euro-American consensus for entry-level and advanced practice competency; provide a framework for a national and international initiative on how NMT and NMR roles and clinical career ladders may be developed; facilitate learning from others' experience; and encourage NMTs and NMRs to take a critical look at and evolve, where possible, their professional roles. The working party also recognized that although its central remit was to NMRs and NMTs, the contents and philosophy of this document may have value to other nonmedical staff working in nuclear medicine (e.g., nurses, physicists), as they may have similar ambitions toward patient care and management. (In this context, nonmedical staff means those who have not received a medical education that would result in their becoming registered medical practitioners. Examples of medical practitioners would include radiologists and nuclear medicine physicians. Examples of nonmedical practitioners would include nurses, radiographers, technologists, pharmacists, and physicists.)

A draft consultation document was written by August 2010, and key elements of this document have been presented at 4 conferences: World Federation of Nuclear Medicine and Biology, September 2010; EANM, October 2010; Croatian Radiography Conference, 2011; and SNM, 2011. Comments were received from delegates at these events, and some changes were made to the document. An interactive session at the 2011 EANM conference is planned in order to debate several issues within this final version of the document.

\section{AN INTERNATIONAL PERSPECTIVE ON ADVANCED PRACTICE}

To date, several countries have supported their nonmedical workforce in developing competencies and responsibly improving patient care and management. Such progression has required these professionals to work in areas not usually associated with their traditional responsibilities. Development 
of professional roles in this fashion is not without grounds. For instance, there is a significant and growing body of literature (gray and peer-reviewed) that supports the value that this type of role development has in patient care and management, and there is evidence to suggest this is a costeffective way to manage and deliver quality health care. In addition, in certain countries, robust professional and hospital-based mechanisms have been implemented to ensure quality. In some countries, legal arrangements have been modernized to facilitate the formal recognition of advanced practices, and mechanisms have also been put in place to minimize the incidence of clinical negligence claims. The latter obviously seeks to protect professionals as well as patients.

There is a need to universally and constantly improve patient care. Improvement takes many forms but always includes striving to increase the efficiency and quality of care with the goals of a higher standard of patient care and an increase in patient satisfaction. Changes in technology have helped serve as an underpinning to the continual improvement and advancement of the field of nuclear medicine. The technology in nuclear medicine has evolved from the routine clinical use of rectilinear scanners in the 1960s to the routine clinical use of PET/CT scanners in the 21 st century. In addition, the computers and instrumentation used in nuclear medicine have increased in sophistication and complexity of operation. The evolution of such technology has been accompanied by the use of a broader range of radionuclides, as well as advancements and changes in radiopharmaceuticals. As one would expect, changes in radiopharmaceuticals and technology have resulted in both new and modified imaging procedures. The changes in nuclear medicine have not occurred in a vacuum but rather amid continual changes in health care on the whole, including modifications to regulations and laws, accreditation requirements, patient expectations, and professional accountability.

In this constantly changing environment, it has been the expectation of the clinical sites that NMTs and NMRs will find ways to learn and adapt to new technology, radiopharmaceuticals, and procedures. It has also been the expectation that educational organizations will modify curricula to address the current and future needs and practices in the field. Although the expectations and responsibilities of the NMT and NMR have increased greatly over the last 4 decades, in some instances these increases have not always been accompanied by a formal recognition of their practice. Although NMTs and NMRs have long been able to find alternate career paths that match their interests or increased skills and abilities (e.g., management and education), until recently an extended career ladder has not been available within the clinical setting. Today, some countries have encouraged their NMTs and NMRs to enhance the clinical service they offer in order to improve patient care and management, and they have been rewarded for their enhanced contribution with elevated pay scales and a professional career ladder, status, and title that reflect their true contribution.
In several countries, this enhancement of the role of NMTs and NMRs has brought about an increase in their clinical skill and knowledge to a level where they are given clinical responsibilities previously or currently undertaken by medical practitioners. In many instances, medical practitioners have been able to discontinue certain tasks and place their time, energy, and skill into higher-order and more demanding medical challenges. Other examples of an increased level of responsibility include adopting competencies previously restricted to health care professionals other than medical practitioners (e.g., nurses). The NMT and NMR clinical responsibilities that are now in some countries considered advanced (often as a group referred to as advanced practice) are the same as those that have been routine for many NMTs, NMRs, and general radiographers for almost 2 decades.

Because responsibilities among NMTs and NMRs vary between countries, and even within a particular country, one may wonder what responsibilities and requirements exist for becoming or qualifying to become an employment-level NMT or NMR and what responsibilities would be considered to be advanced practice. Each country has its own requirements for becoming an NMR or NMT, and generally the requirements involve a program of study that includes theory and practice. In many countries, there is a requirement to formally assess an individual's competence to practice and an individual's knowledge of the theory that underpins competence in the field. In addition to the marked variations in formative professional education between and within countries and the differences in expectations about the skill and ability of NMTs and NMRs on qualification and entry into the field, there are also differences in postqualification educational opportunities and requirements.

Differences in formative professional education and postqualification education, politics, culture, and regulations and laws tend to be reflected in the clinical responsibilities in which NMTs and NMRs might engage, both on qualification and throughout their practice. Given the differences in competencies, skill sets, and clinical responsibilities at the level of entry into the profession, it is natural that there would be differences among the countries with respect to the characterization of what might constitute an advanced role for NMTs and NMRs. Simply put, one country might recognize a specific role or competency as one that would be included in formative professional education, whereas another would see the same role or competency as advanced practice because it would be acquired in a postqualification framework. Therefore, at present, no clear international statement of intent for advanced practice exists. Some might argue such statements should exist and may involve the following:

- The competence and skill set would be one that is acquired after basic training.

- The competence and skill set would be at a higher cognitive and clinical level than basic training or formative professional education. 
- The competence and skill set would seek to improve patient care and management.

- The competence and skill set would seek to offer opportunities for clinical career progression.

- The scope of the competence and skill set would vary widely between countries, because of factors such as laws, politics, culture, and economy.

In addition, there is no internationally agreed-on statement on what would be considered to be entry-level competencies. Perhaps the entry-level competence and skill set might be defined as follows:

- The competence and skill set would be that considered necessary to ensure that nuclear medicine procedures are conducted to an appropriate level.

- The competence and skill set would be acquired during basic training or formative professional education.

- The scope of the competence and skill set would vary between countries, because of factors such as laws, politics, culture, and economy.

- Any agreed-on international entry-level list of skills and competencies would likely be small because of the above factors.

Figure 1 illustrates the present situation, which includes a marked variation of views on entry-level and advanced practice. The entry-level zone in Figure 1 could represent an agreed-on common set of competencies and responsibilities for all countries. The advanced practice 1 zone contains those competencies and responsibilities that some countries might view as advanced; however, some or many of these competencies could be viewed as entry level by other countries. This difference of views explains why Figure 1 has 2 zones for advanced practice. The advanced practice 2 zone would be acknowledged by all countries

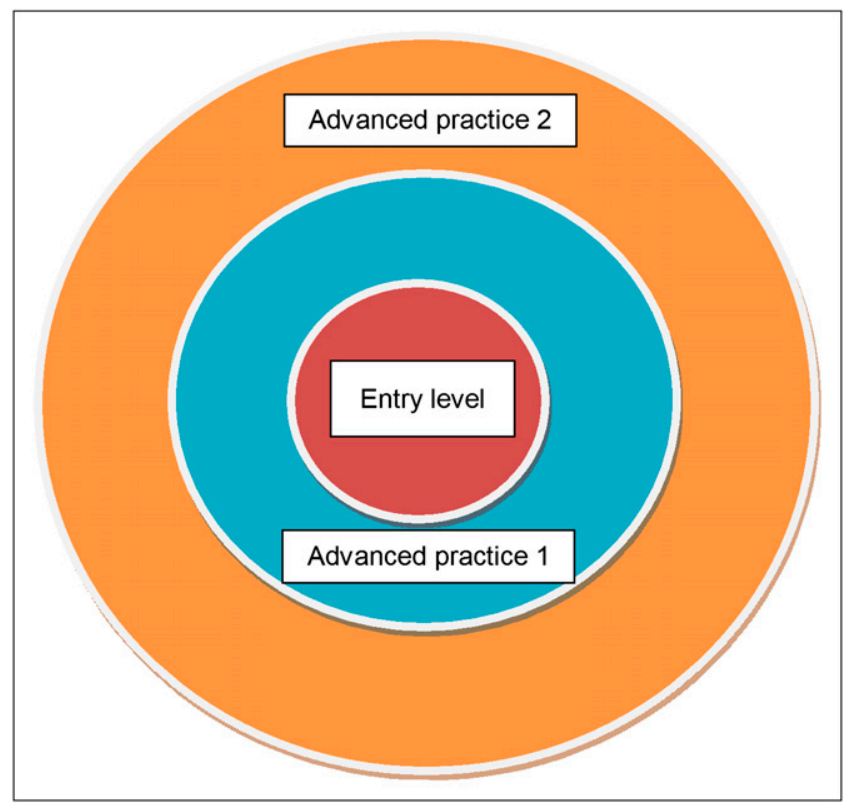

FIGURE 1. The present situation: a marked variation of views on entry-level and advanced practice. as containing advanced competencies and responsibilities; all of these would be engendered in a postqualification framework and not included within formative education and training. With these arguments in mind, it could be, for this model, that the entry-level range of competencies and responsibilities could be relatively small, because if not there would be potential for excluding some countries that have smaller ranges of competency and responsibility. The purpose of this document is to be inclusive and not to exclude any country or professional group within a country.

In this document, we do not seek to argue the precise detail of what would or would not be included within entrylevel, advanced practice 1, or advanced practice 2 zones; rather, we wish to reach a common understanding that the model in Figure 1 could represent adequately an international perspective for entry-level practice and advanced practice. With this international perspective in mind, we believe it would not be right for any individual or country to comment critically on the scope of practice (entry level or advanced) of another country-principally because it is unlikely one would have an adequate understanding of the underlying professional, political, legal, financial, cultural, and social contexts. We should simply acknowledge that differences will exist, and we should acknowledge and value these differences accordingly. If the principle of advanced practice zones 1 and 2 is acknowledged, it follows logically that an advanced role or competency to one country might be recognized as entry level by another; the reference point for role or competency classification and recognition would be set nationally and not internationally. An agreed-on international statement could be that a practice would be characterized as advanced if the role is perceived to require postqualification education and training and would demand a higher cognitive and skill level than that engendered during formative professional education.

With the above proposal in mind, each country could create its own national model for entry-level and advanced practice, as illustrated in Figure 2. The purpose of this activity would be to help set out a national initiative on how NMT and NMR roles could develop. We acknowledge that this approach will still result in difficulty with respect to the portability of the title of NMT or NMR and the ability to use that title outside the home country. As yet, we are not proposing an internationally agreed-on range and scope of competencies for entry-level or advanced practices. However, the proposal in this document would form a first and important step toward establishing internationally accepted roles, responsibilities, competencies, and scope of practice for entry-level and advanced practice and would outline a possible route for clinical career progression.

In some countries, such as The Netherlands, the entrylevel requirements are broad and include competencies in several medical imaging modalities as well as radiation therapy. In such countries, a need may exist to create a rung on the career ladder that precedes entry-level NMT and NMR, such as an NMT assistant, radiographer assistant, or 


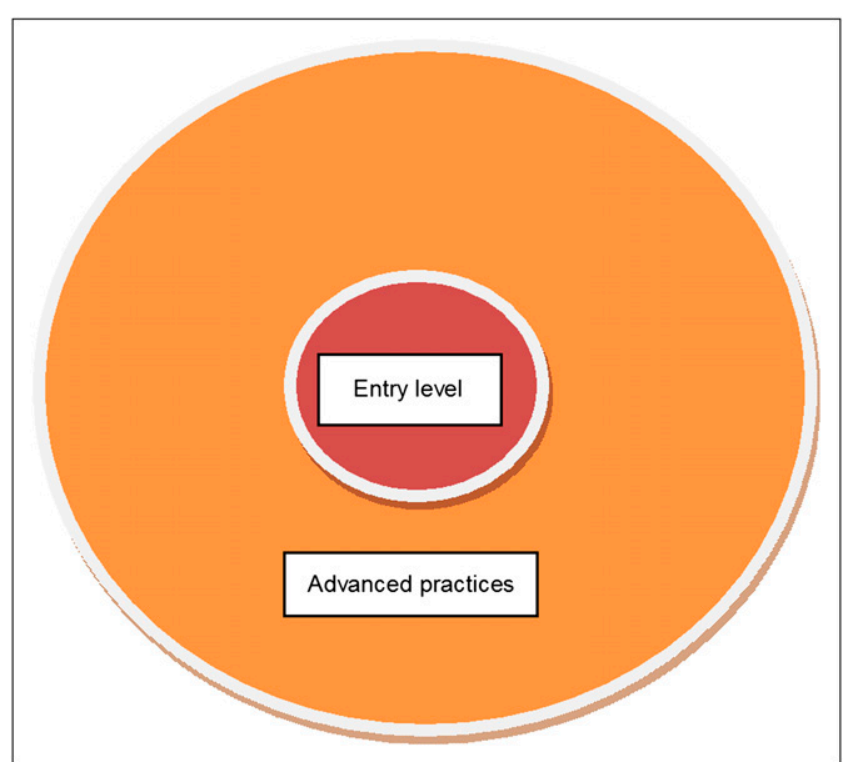

FIGURE 2. Each country could populate its own national model for entry-level and advanced practice.

nuclear medicine assistant. At this level, the individual would have roles and responsibilities that are not as inclusive as those of an entry-level NMT or NMR. Such a career framework model has existed within the United Kingdom for almost a decade, where a technical grade (or employment level) below that of radiographer or NMT exists. Individuals in these positions have responsibilities that are less than those of an NMT or radiographer but support the work of NMTs and NMRs. Interestingly, performing imaging procedures under the supervision of a qualified staff member, such as an NMT or NMR, is often part of the assistant's role. Elaborating further on United Kingdom experience, there are 4 tiers within its radiographer and allied professions career ladder (examples of allied professions include physicist, clinical scientist, radiographer, nurse, and physiotherapist):

1. Assistant practitioner.

2. Practitioner (e.g., radiographer).

3. Advanced practitioner.

4. Consultant practitioner (this is the pinnacle clinical grade within the United Kingdom, and all allied health professional groups can achieve the same title status and scope of practice and pay scale).

\section{RATIONALE FOR ADVANCED PRACTICE}

Advanced practice should not be without a rationale, and on reviewing the literature and listening to a range of people in several countries, we have identified 3 beneficiaries: the patients, the NMRs and NMTs themselves, and the services as a whole.

Advanced practice has demonstrated many benefits to patients, including increased efficiency (e.g., speed of service) and enhanced quality of care. Interestingly, in some clinical settings, access to medically trained person- nel (e.g., physicians) is limited, and we have found that having practitioners with advanced skills available brings many benefits to patients.

There is a clear value to having NMTs and NMRs perform advanced roles. We have found that some staff have been conducting advanced practices for quite some time but have not been formally valued or recognized for their additional skills. When advanced practice has been formally introduced, these staff have been enabled to legitimately conduct these roles and also be valued for them. Several countries have established clinical career ladders for those with advanced competencies. In the United Kingdom, for instance, 2 relatively new grades have been introduced to reflect the enhanced level of responsibility and increased scope of practice: advanced practitioner and consultant. Such grades define the status of those practicing at these levels. Alongside these new career structures come improved clinical pay scales, thereby reflecting the value and importance of the clinical work being conducted. Finally, NMTs and NMRs who engage in advanced competency roles have higher job satisfaction; this fact was established from the literature and also through listening to those who engage in these activities. Perhaps a related added benefit (which also has clear value to the service and the patient) is that retention of goodquality clinical staff can now be facilitated through advanced practice, through benefits such as enhanced satisfaction, pay, and status.

The service as a whole can benefit too. Many published studies illustrate the increase in efficiency brought about through the introduction of advanced practices-efficiency resulting in part from cost reductions (e.g., completion of a task by a staff member who is paid less). There is also considerable evidence to demonstrate much better use of staff capability.

\section{EXAMPLES OF ADVANCED PRACTICES}

Using our earlier definitions of advanced practice, we have solicited opinions from several countries of what could constitute specific examples. The first set of advanced practice examples includes scanning the patient, processing images, caring for and managing patients, and performing quality control tests of equipment. In some countries, this set is not covered in basic training and formative education and, consequently, is not part of the basic job role; these skills might be (but are not always) engendered after qualification. Strictly speaking, using our proposed definitions, they would be classified as advanced practices. Questions are therefore raised; for instance: "Should there be a minimum requirement for entry level?"and "If so, should a date be set by which all countries would agree to achieve the minimum requirement in order for an individual to be considered an NMR or NMT?"

Other examples of advanced practices were also identified, and these are outlined in Table 1. On considering some of the examples in Table 1 during our consultation exercises 


\begin{tabular}{|c|c|}
\hline Category of advanced practice & Examples \\
\hline Medication management & $\begin{array}{l}\text { Deciding when medication needs to be stopped } \\
\text { Deciding when to give medication (adjunct) } \\
\text { Deciding what dose to give } \\
\text { Assessing for contraindications or drug incompatibilities } \\
\text { Administering medications } \\
\text { Responding to adverse reactions (minor and major) } \\
\text { Writing a report after a reaction }\end{array}$ \\
\hline Nonmedical cardiac stress testing & $\begin{array}{l}\text { Standing in when there is no physician in the stress room } \\
\text { Preparing the patient } \\
\text { Taking the lead in cardiac stressing } \\
\text { Being responsible for monitoring the patient } \\
\text { Taking appropriate action if the patient has a problem } \\
\text { Deciding when to administer a radiopharmaceutical } \\
\text { Deciding when to cease a stress test } \\
\text { Responding to cardiac events; deciding when help is required }\end{array}$ \\
\hline X-ray imaging & $\begin{array}{l}\text { Requesting before ventilation-perfusion imaging } \\
\text { Requesting to investigate unexplained hot areas seen on a bone scan } \\
\text { Requesting CT after SPECT to establish } \\
\text { Precise location (could be low-dose CT) } \\
\text { Diagnosis (diagnostic-quality or high-dose CT) }\end{array}$ \\
\hline Surgical preparations (mark up for surgery) & $\begin{array}{l}\text { Being involved with nuclear medicine scanning } \\
\text { Identifying the nodes on a scan } \\
\text { Marking skin to suggest where the node is for the surgeon }\end{array}$ \\
\hline Formal reports about scans & $\begin{array}{l}\text { Describing what is seen } \\
\text { Noting whether there are incidental findings and whether they are } \\
\text { clinically significant } \\
\text { Answering the clinical question } \\
\text { Making a (pathologic) diagnosis or indicating normality } \\
\text { Suggesting a prognosis based on scan findings } \\
\text { Suggesting the next step (e.g., further imaging) }\end{array}$ \\
\hline Radionuclide therapy sessions & $\begin{array}{l}\text { Assessing the clinical presentation } \\
\text { Evaluating information from the diagnostic work-up } \\
\text { Deciding whether the case is suited to radionuclide therapy } \\
\text { Taking a lead role in calculating the dose } \\
\text { Preparing the patient for the dose; including assessment of } \\
\text { contraindications } \\
\text { Administering the dose } \\
\text { Assessing the patient for complications } \\
\text { Following up the patient }\end{array}$ \\
\hline
\end{tabular}

in various countries, questions have come up about where the limit of advanced practice might be, such as "At what point would you have to be medically trained to assume a particular responsibility?" As with the entry-level question, we have not attempted to answer this question but have included it as food for thought.

\section{EVOLUTION OF PROFESSIONAL RESPONSIBILITIES}

We acknowledge that legitimate differences exist between countries, such as differences in culture, politics, economics, regulations, and laws. We should also accept that professional roles evolve over time and that the roles of different professional groups may overlap. This has been recognized in some countries (notably the United Kingdom) and is illustrated conceptually in Figure 3, which compares entry and advanced levels in 1990 and 2010.

Figure 3 shows that, for a particular professional group, the number and range of entry-level competencies can in- crease over time; the range was narrower in 1990 than in 2010. Similarly, the number and range of advanced practices has increased over time. What this simple illustration does not reflect is that the complexity of the competencies can also increase over time. Within the United Kingdom, both the range and the complexity of entry-level and advanced practice competencies have increased over time as the field has continued to evolve. Such evolution of the field of nuclear medicine can also involve evolution of the responsibilities and competencies as they move from one role to another. For instance, the assistant NMR or assistant NMT could move into responsibilities normally associated with NMRs and NMTs. It is therefore fair to assume that entry-level and advanced practice competencies would be dynamic and would likely reflect the needs of any given health care system at a particular point in time, on the assumption that the roles keep up to date with clinical and other demands. 


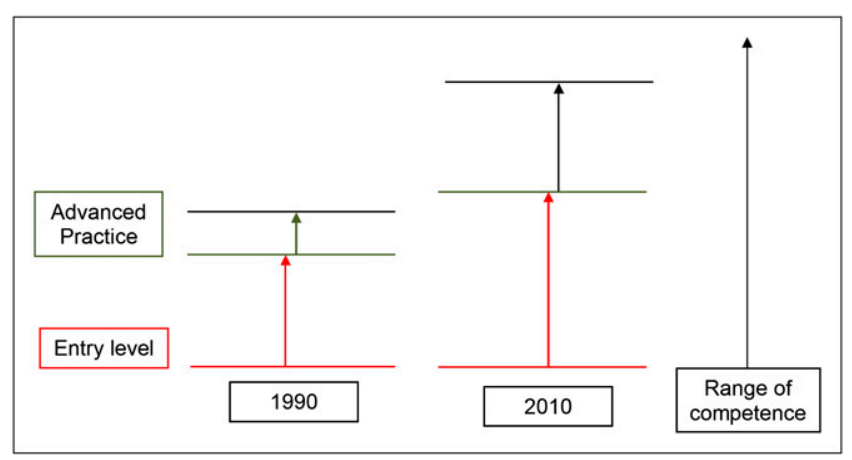

FIGURE 3. Comparison of entry and advanced levels in 1990 and 2010.

It has probably become clear by now that for a professional role to expand, another professional role may have to contract on the point of overlap. Alternatively, it could be that a novel technique is introduced on which no one profession has had a monopoly, and as such, roles would be up for negotiation from the outset. Of course, the professional whose role is being eroded at a specific point might in fact have role expansion into other areas. A notable example within nuclear medicine might be a medical practitioner who has taken on new and more complex roles in PET/CT and still is expected to cover existing responsibilities within routine nuclear medicine. Let us return to role erosion - the effective relinquishment of an aspect of responsibility. Building on the concept of Figure 3, Figure 4 illustrates how, within the United Kingdom, the nursing profession has negotiated roles that were formerly within the domain of the medical profession. As illustrated, in 1990 the overlap between nurse and physician within the United Kingdom was minor; by 2010, that overlap had grown because of nurse advanced competencies. In fact, for certain responsibilities many doctors simply moved on from those roles into more complex roles that made better use of their medical training, as illustrated by the area entitled "new roles." In the United States, the role of nurse practitioner was introduced for the same purpose. The literature has many examples of role evolution. Considering Figure 3 again, as the vertical line for advanced practice increases, it is likely that the overlap into another professional group will increase and the interprofessional boundary will become blurred; it may also shift over time. Blurred areas of overlap could easily result in the existence of 2 professional groups that have many of the same job roles for a period of time, and for certain practice areas this is extremely common within the United Kingdom. This type of change has met with resistance and at times caused conflict among health care professionals within both the United Kingdom and the United States and will no doubt cause concern and conflict elsewhere.

A conflict between roles can arise from 2 likely sources of resistance to change: the person giving up a role and the person taking on an additional role. The receiver of a new role may not wish to take on an advanced role and added responsibilities; equally, the person giving up a role may not wish to do so. Clearly, there should be a negotiation between the stakeholders. Interestingly, in the United Kingdom, a government consultation exercise indicated that the patients and public alike welcomed the notion that professionals who were capable of carrying out a responsibility or task should be allowed to perform that responsibility or task and that a professional title should not be a limiting factor.

\section{LEADING AND MANAGING CHANGE}

In light of the changes in roles needed to keep pace with changes in the clinical workplace, this document is proposing that NMTs and NMRs take a critical look at their current and potential future roles. Because a future role may include the overlapping of responsibilities with another health care professionals' current role, it would be naivve to assume that this process would not meet with anxiety and even resistance within the 2 professional groups or even within professional groups that work closely with NMTs and NMRs.

For the proposals within this document to be realized, new ways of thinking would need to be adopted and new ways of working would be required. Current and perhaps long-held values and beliefs might be challenged, and this would have an impact on hospitals and educational establishments. Therefore, early inclusion of all stakeholders in the process of change is advisable. As is well described within the leadership and management literature, when something new is considered, some people seize the opportunity whereas others become highly resistant and entrenched and can engage in a range of counterproductive and often destructive behaviors. Strategies have been described in the literature to help people manage their own emotions and actions and those of others, so that a positive process can be embraced and mutually agreeable outcomes can be achieved. It is well

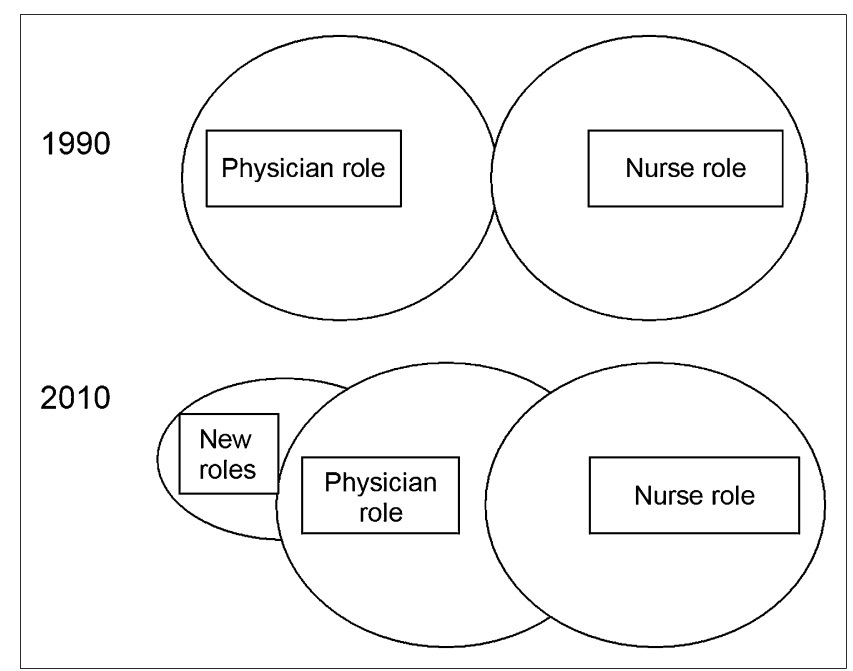

FIGURE 4. Illustration of how, within the United Kingdom, the nursing profession has negotiated roles that were formerly within the domain of the medical profession. 
TABLE 2

Factors That Can Facilitate and Inhibit Process of Change

\begin{tabular}{ll}
\hline \multicolumn{1}{c}{ Facilitator } & Barrier \\
\hline Laws or regulations that enable change & $\begin{array}{c}\text { Laws or regulations that restrict advancement } \\
\text { of a role or change in responsibilities }\end{array}$ \\
$\begin{array}{ll}\text { Guidelines for practice that enable change } \\
\begin{array}{l}\text { Presence of key players who support the } \\
\text { desired change }\end{array}\end{array}$ & $\begin{array}{l}\text { Fear of litigation } \\
\text { Presence of trainee doctors who want roles } \\
\text { that allow them to develop }\end{array}$ \\
$\begin{array}{ll}\text { Shortage of nuclear medicine physicians } & \text { Fear of change } \\
\text { Financial pressure in the health care sector } & \text { Fear of losing money in cases of fee for service } \\
\text { Effective use of the potential skills and capabilities of all professionals } & \text { Fear of losing turf } \\
\text { Role models who already do advanced practices } & \text { Fear of losing power and status } \\
& \text { Conflict about roles } \\
\text { Inability to support suitable advanced practice } \\
\text { education and training }\end{array}$ \\
\hline
\end{tabular}

worth consulting such literature before approaching any change in the management situation. Many years after a change, differences of opinion can still exist, and from time to time old arguments can resurface; this should be viewed as natural. In the context of NMT and NMR advanced practice, some factors that can facilitate and inhibit the process of change are illustrated in Table 2.

At all stages, effective leadership skills are required across all professional groups. Effective leadership will require involving the right people at the right time, including those with political authority and political power. In most countries, these people would normally include members of the medical profession, as they often have positions of power that can inhibit or effect change. An effective communication strategy is necessary to promote a clear understanding of what is being proposed and how it might be achieved. Sharing of experiences, with respect to implementing change and adopting advanced competencies or even extending the entry-level scope of practice, may serve as a catalyst to inspire others. There will be a need to help those in NMT and NMR professions, as well as those in other professions, to understand that advanced practice can bring significant benefits to patient management and care. Discussions and debates will be required, and the articulation of proposals for and against the adoption of advanced practices may also be necessary. The arguments for the change will undoubtedly emphasize how patient care will be enhanced and perhaps also how financial savings might be brought about and how careers can be enhanced.

Advanced practice is not for everyone. Some experienced NMTs and NMRs may not be interested in adopting added responsibilities and may not value the change.

Those countries that have ventured into advanced practice have found that the transition process takes time. The process is evolutionary, not revolutionary. The first step could be small and cautionary; after critical reflection on this step, an informed decision would be made on what to do next. Figure 3 illustrates, conceptually, how role evolution has occurred over a $20-y$ period.
NMTs and NMRs may be allowed to practice certain competencies by the laws of some countries but prohibited from so doing by the laws of other countries. The methods used to influence a change in laws and regulations will also vary among countries, but in all situations, it is important to include all stakeholders early in the development stage. This approach will provide those in a position of national responsibility with an understanding of the purpose of advanced practice and the need to modernize laws and regulations to accommodate the proposed change. It may also help to achieve buy-in and acceptance early in the process, thereby circumventing obstacles to change. For new areas of practice (e.g., PET/CT), it may be important to implement changes in laws and regulations, or in the scope of practice related to who can perform the procedures, before the equipment enters routine clinical use or as soon thereafter as possible.

\section{EDUCATION AND COMPETENCY}

Educational programs for advanced practices should include theory, practice, and formal assessment of competencies. Of those countries that have implemented advanced practices, the educational framework in which they are engendered tends to be postgraduate-for example, a master of science degree, postgraduate diploma, or postgraduate certificate-and builds on an undergraduate education that is generally at the bachelor's degree level.

The rationale for selecting a postgraduate framework for advanced practice is based on the philosophy that advanced competencies include clinical skills at a higher level of responsibility and ability than those of the experienced NMT or NMR and that acquiring these skills demands the development of intellectual acuity in a critical and reflective fashion. The depth of understanding demanded by the critical and reflective approach is often best served through postgraduate study. Consequently, advanced practice requires higher clinical skill sets and higher-order cognitive processes, or a combination of the ability to reason from a conflicting evidence base and the ability to apply that 
reasoning to decision making during common or even novel clinical encounters.

Arising from the autonomy associated with these aspects of advanced practice is a component of clinical leadership. The advanced practice NMR or NMT would be expected to apply knowledge to improve service delivery (e.g., establishing clinical benchmarks) and evidence-based practice and to disseminate the information learned. Another aspect of leadership is the expectation to participate in research and publish the results, some of which may be used to establish benchmarks.

The consideration to adopt advanced practice requires a radical rethinking of formative and postbasic educational curricula, not simply in terms of syllabi content but in terms of the depth and level to which the material is taken, as well as how cognitive and psychomotor skills are assessed.

\section{EVALUATION OF ADVANCED COMPETENCIES THROUGH AUDITING}

Some countries regulate their health care professionals with a firm intention of protecting patients and the public from poor practice; such regulation seeks to identify and then deal with poor performers, both at the level of entry into the field and at the level of advanced practice. Evaluation and auditing of those who engage in advanced practice can generate data with respect to these intentions but also data that can be used to show others whether they are effective in their new role with respect to facilitating patient care, creating patient satisfaction, and having a positive effect on the financial bottom line of the department. These data would have value to the employer and also to the health care community generally.

Various types of audits exist for advanced practice, but generally the approaches fall into 2 categories: internal and external. Of the methods described in the literature, internal audits have tended to involve electing a clinical professional (e.g., a radiologist) to be the reference standard against which the person performing the advanced practice is compared. In the case of image reading or interpretation, this comparison could involve analysis of parameters such as sensitivity and specificity. However, this sort of approach has come under scrutiny recently because of its lack of robustness, most notably because the local standard (radiologist) might not be a suitable gold standard: "To err is human." Consequently, there has been a move toward more robust audit designs. A progressive example of an external audit can be found in the field of mammography within the United Kingdom. There, on an annual basis, all mammography film reporters are highly encouraged to participate in an annual external audit in which they receive 120 cases to report. The data are analyzed centrally, and reporters receive their own sensitivity and specificity score, which should be given to their manager during yearly staff performance reviews. Interestingly, this external audit is profession-independent, or in other words, both radiologists and radiographers participate in the external audit. These national data have demon- strated no significant difference in specificity and sensitivity between these 2 professional groups, and radiographers and radiologists each hold about $50 \%$ of the national image reporting responsibilities for the United Kingdom breast screening program. Radiographers and radiologists perform similarly.

Various methods exist on how to perform audits; no single one is most correct. The important point is that audits of advanced practice should be performed and that, as required, action should be taken on the outcome. It might be that the process demonstrates the right standard is met; it might be that if the right standard is not met then a period of further training would be required.

\section{CONCLUSION}

With increased communication and collaboration among the nuclear medicine professional organizations and countries around the world, NMTs and NMRs are in a strong position to collaborate in order to respond to matters of common interest. One area would be to agree on some points of principle for entry-level competencies as a first step toward improved mobility between countries. Another area would be to consider whether advanced competencies are of value in different countries and, for those who feel they are valuable, to provide support mechanisms for implementing them into practice.

In this document, we have set out some important issues that need consideration if a country wishes to introduce advanced practices. The working party now needs to consider the next steps. Although these still need to be agreed on, some initial thoughts have surfaced: forming an implementation and support group to assist those countries wishing to introduce advanced practices, and extending the initial working party to include representation of a broader range of countries (i.e., outside Europe and America) with a more global perspective.

\section{ACKNOWLEDGMENTS}

The authors would like to acknowledge the following individuals for their assistance: Wim VandenBroek, The Netherlands; Claudiu Pestean, Rumania; Marianne Federspiel, Denmark; Tone Eriksen, Norway; Geraldine Philotheou, South Africa; Julie Nightingale, England, United Kingdom; and Heather Patterson, Australia. No potential conflict of interest relevant to this article was reported.

\section{SELECTED READING}

Reporting by Radiographers: A Vision Paper. London, U.K.: College of Radiographers; 1997.

Berman L, de Lacey G, Twomy E, et al. Reducing errors in the accident department: a simple method using radiographers. Br Med J (Clin Res Ed). 1985;290:421-422.

Clinical Radiology: A Workforce in Crisis. London, U.K.: Royal College of Radiologists; 2002.

Hulbert DC, Riddle WL, Longstaff PM, et al. An audit of litigation costs in four accident and emergency departments. J Accid Emerg Med. 1996;13:400-401.

Culpan DG, Mitchell S, Hughes M, et al. Double contrast barium enema sensitivity: a comparison of studies by radiographers and radiologists. Clin Radiol. 2002;57: $604-607$. 
Murphy M, Loughran CF, Birchenough $\mathrm{H}$, et al. A comparison of radiographer and radiologist reports on radiographer conducted barium enemas. Radiography. 2002;8: 215-221.

Hogg P, Holmes K. Reporting for the technologist. In: Proceedings of the 28th Annual Meeting of British Nuclear Medicine Society; May 2000; Edinburgh, Scotland.

Hogg P, Holmes K. Interpretation of nuclear medicine data by non-medical health care professionals: developments in the United Kingdom. J Diagnostic Radiography Imaging. 2000;3:77-85.

Piper KJ, Paterson AM, Godfrey RC. Accuracy of radiographers' reports in the interpretation of radiographic examinations of the skeletal system: a review of 6796 cases. Radiography. 2005;11:27-34.

Loughran CF. Reporting of fracture radiographs by radiographers: the impact of a training programme. Br J Radiol. 1994;67:945-950.
Robinson PJ, Culpan G, Wiggins M. Interpretation of selected accident and emergency radiographic examinations by radiographers: a review of 11,000 cases. $\mathrm{Br} \mathrm{J}$ Radiol. 1999;72:546-551.

Donovan T, Manning DJ. Successful reporting by non-medical practitioners such as radiographers, will always be task-specific and limited in scope. Radiography. 2006;12:7-12.

Robinson PJ. Radiology's Achilles' heel: error and variation in the interpretation of the Rontgen image. Br J Radiol. 1997;70:1085-1098.

Rudd PD. The development of radiographer reporting 1965-1999. Radiography. 2003;9:7-12.

Meek S, Kendall J, Porter J, Freij R. Can accident and emergency nurse practitioners interpret radiographs? A multicentre study. J Accid Emerg Med. 1998;15:105-107.

Paterson AM, Price RC, Thomas A, Nuttall L. Reporting by radiographers: a policy and practice guide. Radiography. 2004;10:205-212. 